Cuadernos de Filología Clásica. Estudios Latinos ISSN: 1131-9062

http://dx.doi.org/10.5209/CFCL.62521

\title{
La polivalencia de Germánico en Fasti
}

\author{
Maricel Radiminski ${ }^{1}$
}

Recibido: 29 de agosto de 2017 / Aceptado: 30 de septiembre de 2018

Resumen. La clasificación genérica de Fasti de Ovidio es un asunto muy debatido por la crítica a raíz de la convivencia de elementos propios de distintos códigos literarios en el texto tales como la elegía, la poesía didáctica y la épica. Dado que este poema parece definirse a partir de la indefinición misma, vale pensarlo como una suerte de híbrido textual. A este respecto, la figura de Germánico, dedicatario del poema y partícipe relevante de dos elegías del exilio (Ex Ponto 2.1 y 4.8), se construye como un personaje propiamente dicho que da cuenta de esta hibridez o mixtura. La configuración del personaje de Germánico como hombre de letras, de armas y de poder exhibe la combinación de diversos elementos genéricos y lo vincula con distintos aspectos propios del texto. Nos proponemos demostrar que la caracterización plurivalente de Germánico en Fasti remite, desde un punto de vista metapoético, a la configuración genérica del poema ovidiano.

Palabras clave: Ovidio; Fasti; Germánico; personaje; géneros literarios

\section{Polyvalent Germanicus in Fasti}

Abstract. The generic status of Fasti is a crucial issue in Ovidian scholarship, because of the interlocking of different literary codes within the text, such as elegy, didactic poetry and epic. Since the poem arises from its own indefinition, it can be seen as a sort of literary hybrid. Germanicus, both the poem's addressee and a relevant figure of two exile elegies (Ex Ponto 2.1 y 4.8), is built as a character in the strict sense that makes clear the poem's hybridization or mixture. The configuration of the character of Germanicus as a man of letters, arms and power exhibits the combination of diverse generic elements and links them with different aspects of the text. I aim to show that the polyvalent construction of Germanicus in Fasti relates, from a metapoetic viewpoint, to the generic nature of Ovid's poem on Roman time.

Key words: Ovid; Fasti; Germanicus; Character; Literary Genres

Sumario: 1. Introducción. 2. Germánico: figura y personaje. 3. Germánico en Ex Ponto 2.1. 4. Germánico en Ex Ponto 4.8. 5. Germánico en Fasti. 6. Conclusiones. 7. Referencias bibliográficas.

Cómo citar: Radiminski, M., «La polivalencia de Germánico en Fasti», Cuad. Filol. Clás. Estud. Lat. 38.2 (2018), 175-192.

\footnotetext{
1 Universidad de Buenos Aires. Facultad de Filosofía y Letras; CONICET.

E-mail:maricelradiminski@gmail.com
} 


\section{Introducción}

Fasti de Ovidio es un texto genéricamente ambiguo: al tratarse de un poema acerca del calendario romano, se vincula directamente con el poder político y parece acercarse a géneros literarios dignos del hexámetro como la poesía didáctica o la épica; sin embargo, al plasmarse en dísticos elegíacos, originalmente consagrados a asuntos menores, remite también a la elegía. El texto posee, de hecho, algunos elementos propios de la poesía didáctica ${ }^{2} \mathrm{y}$, a pesar de que el ego enunciador dice alejarse de los asuntos bélicos desde el comienzo del poema (Caesaris arma canant alii nos Caesaris $\left.\operatorname{aras}^{3}, 1.13\right)$ y crea, como nota Barchiesi $(1997,19)$, un marco de paz que hace de Fasti la obra ovidiana más alejada de la temática de los arma, recupera, a lo largo de su desarrollo, algunos rasgos propios del género épico. Estas características textuales se tornan particularmente significativas en relación con el metro del poema, en virtud de la plurivalencia que supone la intersección de tales rasgos genéricos. No obstante, según señala Conte (1992, 107-109), lo distintivo de un género literario no funciona aisladamente sino dentro de un sistema más amplio en el que intervienen otros elementos que resultan representativos pero no necesariamente exclusivos de cada código. Los géneros son, entonces, sistemas de signos que entran en relación con sus opuestos y producen significado a partir de diversas interacciones entre los mismos. La combinación de marcas genéricas es incluso un elemento constitutivo de la elegía, a la que Harrison $(2002,79)$ denomina atinadamente «supergenre» por la variedad de asuntos y estilos que la definen. En esta línea, entendemos que la coexistencia de rasgos y estilemas genéricamente diversos en Fasti plantea la indefinición como una característica propia del texto y, por ende, permite considerarlo como un constructo híbrido 4 .

A su vez, el contexto de producción del poema ovidiano remite a un período de vaivenes políticos y sociales. Al ubicarse entre el fin del siglo I a.C. y el inicio del siguiente, el texto es testigo de la muerte de Augusto y del consecuente paso del principado al imperio de Tiberio. Dicha etapa incluye, además, la relegatio del poeta en 8 d.C. y la posterior revisión de Fasti en Tomi, cuestión que marca la ineludible relación entre el poema, la literatura ovidiana del exilio y el poder político ${ }^{5}$. En este sentido, nos resulta interesante la inclusión de la figura de Germánico en Fasti, ya que no solo se trata de una personalidad contemporánea a Ovidio y a la confección de su calendario, sino que su participación como dedicatario del texto y numen patrocinador ${ }^{6}$ remite a dos instancias clave del quehacer poético. Por un lado, como afirma Genette $(2001,101)$, la dedicatoria de un texto, habitual en la literatura romana de la época, solía apelar a una suerte de protector o benefactor de quien se esperaba cierto favor. Según el autor (ibid., 113) podía ser un dedicatario privado (es decir, allegado al círculo del autor) o público (una persona conocida por otras,

Toda situación didáctica requiere de un magister que enseña, un discipulus que aprende y un saber que el primero imparte al segundo. Para las características de este género, $c f$. Dalzell (1996, 8-34); Volk (2002, 25-68); Pozzi (2010).

3 Seguimos el texto latino fijado por Alton, Wormell y Courtney (1985).

4 Dalzell $(1996,136)$ afirma que la totalidad de la obra elegíaca de Ovidio puede considerarse «an experiment in generic variation»».

5 Señala Newlands $(1995,9)$ que «by its witty play with time and literary history, the Fasti offers a major exploration of Roman identity in a period of transition and adjustment in the Roman world».

6 Para Germánico como numen, cf. Fantham $(1985,247)$. 
con la que el autor pretendía plasmar cierta relación de tipo intelectual, artístico, político, etc.). Creemos que este último es el caso de la dedicatoria a Germánico en Fasti pues, al invocarlo, el ego enunciador intenta vincular su obra con todo lo que este personaje representa y, a raíz de ello, dar a su texto un marco cualitativamente relevante y proponer un lector acorde al mismo. A su vez, la dedicatoria de una obra siempre implica cierta ambigüedad, dado que involucra no solo al dedicatario en sí sino también al lector, que participa como testigo de esta dedicatoria y, por ello, de la relación que quien dedica intenta configurar respecto de su dedicatario (ibid., 115-116). En este sentido, vale asumir a este último no como una entidad ubicada en la periferia del material literario propiamente dicho y ajena al texto sino como un personaje más, cuya presencia nunca es inocente ni circunstancial.

Por otro lado, en cuanto a la deidad patrocinadora o musa inspiradora, se trata también de una modalidad recurrente en la literatura romana ${ }^{7} \mathrm{y}$ es, además, frecuente en la poesía didáctica (Pozzi, 2001, 139-140). Al igual que en el caso del dedicatario, se esperaba que dicho agente mantuviera cierta relación con el tema a desarrollar (ibid., 140), cuestión que Germánico cumple con creces en Fasti en virtud de su propio trabajo con los Phaenomena de Arato. Más aún, la identidad de este princeps en el poema de Ovidio se construye a partir de ciertos elementos presuntamente discordantes que parecen vincularse con el plano genérico del texto.

A la luz de estas observaciones preliminares, nos proponemos demostrar que la configuración de Germánico en Fasti es consecuente y determinante respecto de la hibridez genérica de la obra. Para ello, nos detendremos primero en la figura de Germánico en sí y en la construcción de su personaje en las elegías epistolares Ex Ponto ${ }^{8}$ 2.1 y $4.8^{9}$, dada la incidencia de ambas en la escritura de Fasti; explicitaremos luego las correspondencias poéticas y metapoéticas que desencadena la inclusión de dicha figura en esos dos textos del exilio y en Fasti.

\section{Germánico: figura y personaje}

La inclusión de la figura de Germánico en Fasti es elocuente en varios aspectos que, según nos parece, remiten a la práctica literaria ovidiana y a los distintos alcances del poema. En principio, Germánico vivió entre el 15 a.C. y el 19 d.C., con lo cual logró ver el cambio de siglo y el paso del principado augustal al imperio de Tiberio, característica que comparte con la inscripción socio-histórica del calendario ovidiano. Dicha inscripción deja al descubierto la vinculación del poema con el poder político dominante, dado que la figura de Germánico, hijo de Druso (hermano menor de Tiberio) y Antonia (hija de Octavia, hermana de Augusto), se asocia directamente con la gens Iulia, tanto por su filiación parental con Augusto y Tiberio como por el

Fantham $(1985,249)$ y Newlands $(1995,54)$ notan que Germánico parece sustituir a las Musas y a Apolo en sus roles inspiradores.

8 Seguimos el texto latino fijado por Richmond (1990). Para una sistematización crítica de las características y desafíos literarios y genéricos de los textos ovidianos del exilio, $c f$. Claassen (2008). Para algunas consideraciones de la elegía del exilio y su hibridez formal y temática, $c f$. Baeza Angulo (2008).

9 El vínculo entre estas epístolas (sobre todo 4.8) y otras y sus líneas de continuidad en Fasti (mayormente, en 1.3-26) ha sido señalado por la crítica (cf. Fantham, 1985; Herbert Brown 1994, 173-212; Subias-Konofal 2003; Green 2004, 31-44; Galasso 2008; McGowan 2009, 155-164; Rosati 2012; Myers 2014), aunque no se ha abordado la cuestión desde el punto de vista de la hibridez genérica. 
vínculo que el poema guardaba con el princeps, a quien había sido dedicado inicialmente ${ }^{10}$. A su vez, Germánico se había involucrado también en asuntos militares y políticos, como dejan ver sus hazañas en distintos enfrentamientos bélicos ${ }^{11}$ y sus designaciones como cónsul durante los gobiernos de Augusto y Tiberio ${ }^{12}$. Augusto consideró las diversas aptitudes del joven y, ante la ausencia de descendientes masculinos directos que pudiesen continuar con su legado político, lo hizo adoptar por su hijo adoptivo Tiberio, incluyéndolo en la línea sucesoria imperial ${ }^{13}$.

Así como el poema del calendario se configura a partir de elementos genéricos disímiles, el Germánico de Ovidio también parece sustentar las ambigüedades del texto. Además de las mencionadas habilidades militares y políticas, Germánico tenía cierta vocación literaria valorada por su círculo ${ }^{14}$. Si bien es muy poco lo que se ha conservado de sus producciones, se estima que eran de carácter variado y que el sobrino del princeps dominaba las lenguas latina y griega y había intentado desarrollar distintos géneros literarios ${ }^{15}$. No obstante, Herbert-Brown $(1994,176)$ señala que, más allá del reconocido talento de Germánico para la literatura, cabe preguntarse si los alcances de su obra fueron suficientemente significativos como para convertirlo en el dedicatario del poema ovidiano. Según la autora, el único testimonio concreto de la escritura de Germánico son los Phaenomena ${ }^{16}$, una traducción en hexámetros del texto homónimo de Arato que se constituyó en uno de los modelos de los Fasti de Ovidio $^{17}$. Su fecha de composición es incierta, si bien tiende a asumirse que el poeta de Sulmona había conocido el texto de Germánico ${ }^{18}$. Se incluyen también los Prognostica, consagrados a los signos climáticos ${ }^{19}$. Herbert-Brown (1994, 176-177) recuerda que, aunque la autoría de los Phaenomena por parte de Germánico haya sido puesta en duda y atribuida, incluso, a Tiberio ${ }^{20}$, no se trata de una labor literaria original ni de una demostración de talento sino de un simple ejercicio. En efecto, este mismo tipo de trabajo ya había sido emprendido por el joven Cicerón ${ }^{21}$, mientras que

10 Cf. Ov.Tr.2.549-552: Sex ego Fastorum scripsi totidemque libellos, / cumque suo finem mense uolumen habet, / idque tuo nuper scriptum sub nomine, Caesar, / et tibi sacratum sors mea rupit opus. Al respecto, cf. Marcos Casquero (1984, 15-20 y 97); Fantham (1985); Herbert-Brown (1994, 173-185); y Green (2004, 15-25), entre otros.

11 Germánico participó junto a Tiberio de la victoria frente a Panonia, Dalmacia e Iliria, promulgada en el año 9 y celebrada en 12 d.C. ( $c f$. Suet.Tib.16-20; Dio.56.17) y se consagró en Germania, entre los años 10 y 13 d.C. Triunfó nuevamente en 15 y 18 a.C.

12 Fue cónsul en los años 12 y 18 (cf. Suet.Cal.1.1-2).

13 Para cuestiones relativas a los detalles sucesorios y al vínculo entre Germánico y la domus Augusta, cf. Herbert-Brown (1994, 173-185; 196-204); Nicás Montoto (2004, 8-15); Salvo (2010, 138-140).

14 Para las características del círculo de Germánico, cf. Pani (1968).

15 Para una síntesis de la producción literaria de Germánico (astronómica, teatral, oratoria y epigramática), $c f$. Giancarlo (2010, 81-82).

16 Giancarlo (2010, 82-83), cita otros seis epigramas, cuatro en griego (Anthologia Palatina 7.542; 9.17, 18 y 387) y dos en latín (Anthologia Latina 708 y 709) y considera la posible autoría de Germánico. Menciona un séptimo epigrama perdido del que sabemos por Plin.Nat.8.155 que también sería de aquel.

17 Ov.Fast.1.2 (lapsaque sub terras ortaque signa canam) remite a la tradición estelar griega, principalmente representada por Hesíodo y Arato. Cf. Barchiesi (1997, 51-52); Green (2004, 28).

$18 C f$. Herbert-Brown $(1994,177)$. Fantham $(1985,246 ; 254-256)$, entiende que para el momento en que Ovidio revisaba el prólogo de Fasti, Germánico ya había volcado los Phaenomena de Arato al latín.

19 Cf. Herbert-Brown $(1994,176)$.

20 Baldwin (1981) retoma este debate a partir de una revisión crítica de los postulados de Gain (1976), quien deja abierta la contienda acerca de si la autoría de los Phaenomena corresponde a Germánico o a Tiberio. También $c f$. Herbert-Brown (1994, 176); Nicás Montoto (2004, 15).

${ }^{21}$ Cf. Cic.N.D.2.41. 
el neotérico Varrón Atacino y hasta el mismo Ovidio ${ }^{22}$ habrían hecho sus respectivos intentos ${ }^{23}$, de modo que no tendría demasiado sentido apelar a Germánico en calidad de poeta emblemático ${ }^{24}$. No obstante, puesto que la apropiación y reelaboración de modelos literarios anteriores es, como es sabido, uno de los principales mecanismos de la poesía alejandrina a la que Ovidio adhiere, vale suponer que este no consideraría lo anterior como un demérito y que, por ese motivo, la referencia a Germánico podría funcionar como una forma de conectar los Fasti no solo con Arato sino también con prácticas literarias cercanas a las del ego enunciador del poema. Así, la manipulación de la figura de Germánico por parte de Ovidio respondería tanto a motivos políticos y militares como literarios: además de vincularse con el ámbito del poder en Roma, los logros bélicos de este princeps explicarían su representación desde su rol de hombre de armas, y su afición por la literatura permitiría mostrarlo, más allá del impacto real de su obra, como un hombre de letras ${ }^{25}$. En este sentido, señala Rosati que dichos elementos dejan ver un gesto helenístico que convierte a Germánico en el interlocutor idea ${ }^{26}$ de la poesía ovidiana del exilio ${ }^{27}$. En una misma línea, las características de la inclusión de Germánico en Fasti permiten profundizar también la construcción genérica del texto, que, si bien plantea las armas y las letras como asuntos aparentemente excluyentes, se configura a partir del entrecruzamiento de estas materias disímiles.

La inserción de Germánico en Fasti y los aspectos involucrados en ella habilitan el abordaje de su funcionamiento en tanto personaje, es decir, como instancia textual que da cuenta de los estrechos vínculos entre la literatura y el poder, y al mismo tiempo plantea una reflexión literaria y una problematización de orden genérico. Dado que todo personaje se define por sus acciones ${ }^{28}$, resulta necesario entender la caracterización de Germánico en estos términos, sobre todo porque el lector nunca ve en acción al joven príncipe sino que sabe de él por intermedio del ego enunciador. Para ello, revisaremos la participación de esta figura en otros poemas ovidianos del exilio. Además de que muchos de los logros militares de Germánico fueron alcanzados a medida que Ovidio comenzó a incluirlo en sus textos, Fasti parece incorporar los principales lineamientos de esa caracterización, de modo que una mirada intratextual se torna indispensable.

22 Moya Del Baño (1991, 264 n.6) remite a Prob.Verg.Georg.I.138 y Lactant.2.5, 24.

23 Para este tema, $c f$. Calderón Dorda (1990).

24 Baldwin (1981, 164-165) considera la posibilidad de que el mismo Julio César haya creado su propia versión.

25 La crítica ha advertido los roles de Germánico como poeta y guerrero, si bien la configuración conjunta de este personaje como hombre de armas y de letras se enuncia más explícitamente en Subias-Konofal (2003, 110); Galasso (2008, 6); Rosati (2012, 296).

26 Rosati (2012, 296), menciona la imitatio Alexandri a la que aspiraba Germánico, al igual que Pani (1968, 116; 127, n. 42), y Giancarlo (2010, 88-98). Para este tema, $c f$. Braccesi (1987) y Cresci Marrone (1987).

27 King (2004) estudia la figura de Germánico en Fasti en relación con la elegía y la concepción romana de la masculinidad. Plantea que hay un proceso de identificación ambivalente entre Germánico (hombre vinculado con el poder y la oratoria, perteneciente a la elite masculina y ubicado en el centro de Roma) y el poeta (exiliado y alejado de dicho círculo social) que también apela al lector.

28 Castilla del Pino (1989, 21-38) muestra que la identidad o self es la imagen que cada individuo ofrece de sí mismo a partir de sus actos. Esta imagen produce significado y delinea la singularidad propia del personaje. 


\section{Germánico en Ex Ponto 2.1}

Ex Ponto 2.1, datada en el año $13^{29}$, conmemora el triunfo de Tiberio en Panonia (12 d.C.) del que Germánico había participado virtuosamente. El ego enunciador se encuentra relegado en Tomi, alejado de su familia y de su patria ${ }^{30}$, y su deseo de retornar a Roma parece convertirlo, como observa Miller $(2004,212)$ respecto de la poesía ovidiana del exilio, en «an exclusus amator ${ }^{31}$ singing his paraclausithyron ${ }^{32}$ before the locked door that stands between him and the object of desire», lo cual resignifica las valencias eróticas tradicionales de la enunciación elegíaca ${ }^{33}$ : las traslada a un contexto que transforma el dolor amoris en dolor exilii ${ }^{34} \mathrm{o}$ dolor relegationis y también subraya los alcances plurivalentes de este soporte métrico ${ }^{35}$.

Las noticias de Roma y sus éxitos militares parecen alegrar la penosa realidad (nil fore dulce mihi, 2.1.3) del ego exiliado. Aquello $d u l c e^{36}$, término que remite al léxico con el que solían designarse los asuntos amorosos a los que el poeta ya se había consagrado en producciones previas a su exilio, es lo que el ego exclusus no logra hallar en Tomi hasta el presente de enunciación, de modo que dicho elemento activa en este poema una serie de valencias metaliterarias. La buena nueva reconforta al uates y le da ocasión de continuar con su escritura al proporcionarle el tema de su elegía. Esta despliega, pues, el motivo triunfal a través de la Fama (peruenit Fama, 2.1.1; Gratia, Fama, tibi, 2.1.19), quien crea su propio relato (tu mihi narrasti, 2.1.25) y le cuenta al ego que el cese de las lluvias y la salida del sol que acompañaron la victoria se debieron a la voluntad divina (numine caelesti, 2.1.27). La descripción del triunfo culmina con la concesión del perdón a los vencidos ${ }^{37}$ (horum uitam ueniamque tulerunt, 2.1.45), lo cual permite configurar un marco de luminosidad y esperanza con divinidades propicias que el mismo ego enunciador intenta trasladar a su propia situación. Para ello invoca a Germánico, tras esperanzarse con su propio retorno a Roma, al que alude apelando nuevamente a la voluntad divina:

cur ego posse negem minui mihi numinis iram, cum uideam mitis hostibus esse deos?

pertulit hic idem nobis, Germanice, rumor, oppida sub titulo nominis isse tui,

atque ea te contra nec muri mole nec armis nec satis ingenio tuta fuisse loci. (Pont.2.1.47-52)

\footnotetext{
29 Herbert-Brown $(1994,181)$ considera llamativo el hecho de que Ovidio haya hecho esta temprana alabanza, pues Germánico estuvo fuera de Roma hasta el año 12. Presume que, aunque Germánico no podía decidir la derogación del destierro del uates, sí hubiese podido interceder en su favor o bien ante Augusto, o bien ante Tiberio.

30 Sobre estos aspectos de Tristia, $c f$. Tola (2004; 2008).

31 Para este tópico, $c f$. Traver Vera (2011) s.u. «Ronda de amor».

32 Martós Fernández (2011) s.u. «Espera» señala la tortura propia de la expectación causada por este tópico.

33 Para las características del ego enunciador elegíaco, $c f$. Edmunds (2001, 65-82).

34 Miller $(2004,212)$ resalta la simetría entre el mundo del ego amator y el del ego exul. A su vez, Galasso (2008, 6) afirma que «la realtà della vita d'amore dell'autore elegiaco, che conosceva un diretto riflesso nella sua opera, è ora la vita di dolore dell'esilio».

35 Para este tema, $c f$. Nagle (1980).

36 Para este tema, $c f$. Pichon (1991, 135-136).

37 Abordan la clementia de Germánico Herbert-Brown $(1994,181)$ y Galasso $(2008,6)$.
} 
La insistencia en la intervención divina (numinis, 47; deos, 48) posibilita la clausura del destierro del ego, según destaca el primer dístico citado al relacionar a los dioses con el relegamiento y nombrar dos veces al poeta como objeto del mismo (ego ... mihi numinis iram, 47) y al mostrar una alternativa frente a esa situación ( $\mathrm{mi}$ tis hostibus ... deos, 48). La invocación a Germánico destaca sus aptitudes mas las plantea como un rumor (49) desperdigado por la Fama ${ }^{38}$ que no necesariamente tiene valor de verdad ${ }^{39}$. En este sentido se comprende el alcance de los versos siguientes, que vaticinan explícitamente un gran triunfo para Germánico, victoria que también se obtendrá por voluntad de los dioses:

di tibi dent annos, a te nam cetera sumes, sint modo uirtuti tempora longa tuae

quod precor, eueniet (sunt quaedam oracula uatum), nam deus optanti prospera signa dedit.

te quoque uictorem Tarpeïas scandere in arces laeta coronatis || Roma uidebit equis,

maturosque pater nati spectabit honores gaudia percipiens, quae dedit ipse suis.

iam nunc haec a me, iиuenum belloque togaque maxime, dicta tibi uaticinante nota.

hunc quoque carminibus referam fortasse triumphum, sufficiet nostris si modo uita malis,

imbuero Scythicas si non prius ipse sagittas, abstuleritque ferox hoc caput ense Getes.

quodsi me $^{\mathrm{T}}$ saluo ${ }^{\mathrm{P}}$ dabitur ${ }^{\mathrm{H}}$ tua laurea templis, omina bis dices uera fuisse mea. (Pont.2.1.53-68)

El pasaje plantea un paralelismo entre el futuro del ego y el de Germánico, dado que la salvación del primero (que, implícitamente, significa la derogación de su relegatio) se vincula con el triunfo del segundo. La enunciación se centra en las cualidades de Germánico como guerrero al mostrarlo como un personaje capaz de obtener éxitos por sí mismo (a te nam cetera sumes, 53) si los dioses le conceden tiempo. El deseo del ego (di tibi dent annos, 53; quod precor, 55) se convierte en vaticinio (oracula, 55) y se hará efectivo (eueniet, 55) porque, además de contar con su propio respaldo (uatum, 55), tiene el aval de la divinidad (deus ... prospera signa dedit, 56). La profecía del uates explicita el triunfo de Germánico (te ... uictorem Tarpeïas scandere in arces, 57; coronatis ... equis, 58), cuyos logros serán contemplados por la misma Roma. La correspondencia entre la prosperidad de la Vrbs y la victoria del personaje es subrayada, además, por la ubicación de la ciudad y del adjetivo que la define en los dos comienzos de hemíepes del pentámetro 58 (laeta ... $\|^{40}$ Roma ...), verso que remite al género elegíaco y expone ante el lector la conjunción entre el asunto militar y la elegía.

38 McGowan $(2009,158)$ indica que los términos Fama y rumor marcan la distancia entre el poeta exiliado y su fuente de información.

39 Según Verg.Aen.4.178 y Ov.Met.12.53-55, Fama es tan mensajera de la verdad como de la mentira, con lo cual vale sospechar de sus dichos.

40 El signo || señala el corte central del pentámetro. 
El resto del pasaje completa esta configuración del personaje de Germánico a partir de una trama semántica que designa los beneficios que seguirá proporcionándole a Roma la gens Iulia (pater nati spectabit honores / gaudia perpiciens, 59-60), lo cual afirma el vínculo que establece el poema entre Germánico y el poder político a través de la alusión al lazo familiar. El dístico 61-62 resalta la excepcionalidad del personaje (iuuenum ... / maxime) en los ámbitos de la guerra y de la paz, mencionados correlativa y enfáticamente a través de la sucesión de enclíticos (belloque togaque, 61). Queda así delineado el carácter de Germánico en el marco de un vaticinio que asocia sus hazañas con el poder de la palabra poética (oracula uatum, 55 ; a me ... / ... uaticinante, 61-62) y cuyas futuras acciones gloriosas serán un posible asunto para las elegías de nuestro poeta (hunc quoque carminibus referam fortasse triumphum, 63). El adverbio fortasse pone en duda la práctica de esta poesía, cuya posibilidad se ve limitada por las subordinadas condicionales que le siguen (64-66), todas ellas referidas al destierro del ego. Cabe inferir que, si este logra conservar su integridad (presumiblemente, al volver a Roma), podrá entonces dar forma a su carmen, tal como confirma el hexámetro 67 al proponer la posibilidad de salvación del poeta junto con la consagración de Germánico: el paralelismo entre el destino de este último y el del uates es acentuado por la focalización de los términos que los designan entre las tres cesuras del verso, organización rítmica que aúna en el plano léxico a ambos personajes ( $m e$... tua) y distribuye simétricamente a lo largo del hexámetro aquello que compete al enunciador $\left(\right.$ si $m e^{\mathrm{T}}$ saluo $^{\mathrm{P}}$ ) y al receptor (dabitur ${ }^{\mathrm{H}}$ tua laurea templis ${ }^{41}$ ); el último pentámetro sustenta dicha correspondencia al indicar que, si ocurren ambas cosas, los presagios del ego serán doblemente verdaderos (bis ... uera, 68) por cuanto permitirán una y otra consolidación: la del ego y su vuelta a Roma y la de Germánico y sus éxitos militares. El resultado de esa conjunción de elementos serán los poemas del ego (carminibus, 63) y, más específicamente, se tratará de poemas elegíacos (dulcis, 2.1.3), género que, a través del personaje de Germánico, adquiere nuevos alcances.

\section{Germánico en Ex Ponto 4.8}

El personaje de Germánico se afianza en Ex Ponto 4.8, cuya redacción se ubica aproximadamente en los años 15 o $16^{42}$. Esta elegía dirigida a Suilio Rufo, esposo de la hija de la tercera esposa de Ovidio y quaestor de Germánico, confirma la relación entre este último, la literatura y el poder político, que luego será retomada en $\mathrm{Fasti}^{43}$. Al momento de enunciación de Pont.4.8 Germánico ha concretado algunos de los logros militares presagiados en Pont.2.1 por el enunciador, que vuelve a recurrir a aquel. El ego insiste en sus infortunios en Tomi con una callida iunctura que remite al quehacer literario (errorem misero detrahe, 4.8.20) al ubicar el presunto error que

${ }^{41}$ Designamos con los signos $(\mathrm{P}),(\mathrm{T})$ y $(\mathrm{H})$ a las cesuras pentemímeras, triemímeras y heptemímeras del hexámetro respectivamente, siempre que la métrica resulte relevante para nuestro análisis.

$42 C f$. Myers $(2014,725)$. Fantham $(1985,244)$ indica que las afinidades entre Pont.4.8 y Fast.1.3-26 sugieren que fueron compuestos en un mismo período.

43 En nuestro tratamiento de Pont.4.8 y Fast.1.3-26 retomaremos los postulados de Myers (2014), que plantean que la valoración del poder de la palabra poética del ego expresada en la epístola anticipa el proemio de Fasti. 
lo ha llevado al exilio ${ }^{44}$ junto a una marca léxica de la poesía elegíaca (misero) e inscribir así el desarrollo del poema en un marco doblemente político y literario. El agradecimiento a Suilio por su intención de ayudar al ego a retornar a Roma (4.8.122) no es más que un pretexto para introducir la figura de Germánico, que se presenta aquí como la divinidad capaz de favorecer ese regreso:

di tibi sint Caesar iuuenis: tua numina placa.

hac certe nulla est notior ara tibi.

non sinit illa sui uanas antistitis umquam

esse preces: nostris hinc pete rebus opem.

quamlibet exigua si nos ea iuuerit aura,

obruta de mediis cumba resurget aquis.

tunc ego tura feram rapidis sollemnia flammis, et, ualeant quantum numina, testis ero. (Pont.4.8.23-30)

Germánico es ahora tenido por dios (di tibi sint Caesar iuuenis, 23) y su ayuda se presenta como certera (non ... uanas ... / ... preces, 25-26) y, a su vez, en términos metafóricos al aludir al resurgimiento de la pequeña barca del poeta (exigua ... aura, 27; obruta ... cumba resurget $\left.{ }^{45}, 28\right)$. El adjetivo exiguus, comúnmente asociado al género elegíaco, refiere al impulso que necesita el ego para salir adelante y, en este sentido, el motivo tradicional de la cumba como obra elegíaca ${ }^{46}$ permite leer las preces a Germánico como intento de regresar a Roma y como posibilidad de que su barca o práctica literaria pueda llegar a destino. Curiosamente, los inciensos que el ego agradecido llevará a los altares de este dios son sollemnia (29), adjetivo que sugiere una relevancia temática que, a través de la figura de Germánico, habilita el tratamiento de asuntos de mayor envergadura en un soporte elegíaco, tal como ocurrirá en Fasti. De acuerdo con esto, Germánico parece funcionar, en su doble faceta de hombre de bella y toga, como el dios patrocinador de la empresa literaria ovidiana entendida como una práctica en la que confluyen diversos alcances genéricos. Los versos siguientes prolongan este marco estético mediante las disculpas del enunciador ante Germánico por no ofrecerle templos dignos de su numen, lo cual le permite introducir el tema de la poesía en estrecha relación con el poder:

\author{
nec tibi de Pario statuam, Germanice, templum \\ marmore: carpsit opes illa ruina meas. \\ templa domus facient uobis urbesque beatae; \\ Naso, suis opibus, carmine gratus erit. (Pont.4.8.31-34)
}

Como observa Myers (2014, 726-728), la negativa del ego en cuanto al levantamiento de un espacio cultual funciona como una recusatio de la literatura épica al parafrasear e invertir la promesa de Virgilio a Octavio en Georg.3.13 ${ }^{47}$. Nota la autora

\footnotetext{
44 Cf. Tr.2.207: carmen et error.

45 Myers 2014 (726-727) considera este verbo como un anticipo de Fasti.

46 Así Myers describe este motivo (2014, 727).

47 VERg.Aen.3.13: uiridi in campo templum de marmore ponam. Además de Myers (2014), para el vínculo entre Pont.4.8.29-34 y Georg.3.10-14, cf. Galasso (2008, 4) y Rosati (2012, 299-300). Resulta evidente también la relación entre este poema y otros como Hor.Carm.4.8 y 4.9 y Prop.2.10 (cf. Galasso 2008, 1; Rosati 2012; Myers 2014).
} 
que el poeta añade el motivo de la pobreza artística (illa ruina, 32, austeridad propia del exiliado), habitual en el rechazo de los panegíricos épicos, y el ofrecimiento de poesía como único bien material del ego enunciador (Naso suis opibus, carmine, 34) en contraste con los templa que podrán ofrecer las domus ... urbesque beatae (33). Esto parece justificar la elección literaria del uates, pues su ofrenda es humilde ( $p a-$ rua ... uerba, 35-36) pero válida (Nec quae de parua pauper dis libat acerra / tura minus grandi quam data lance ualent, 39-40). El hexámetro conjuga, en sus planos fónico y semántico, los distintos alcances de las afirmaciones del ego pues insiste en la idea de pobreza con una serie de reiteraciones fónicas (PAR $\underline{u} A P A \underline{u} P e R)$; el pentámetro explicita que el soporte de esta ofrenda (tura, designados como sollemnia en 4.8.29) no es menos valioso que aquellos contenidos por estructuras mayores, lo cual vincula nuevamente la práctica literaria del poeta con un ámbito más elegíaco que épico (Myers 2014, 728). Finalmente, la afirmación de 4.8.43-44 (nec tamen officio uatum per carmina facto / principibus res est aptior ulla uiris) alude a Germánico en relación con la conveniencia de los carmina como ofrenda. La correspondencia entre los términos princeps y uir en este contexto parecería sugerir que el officium uatum en cuestión debería plasmarse en versos épicos en virtud de la envergadura del destinatario. Por el contrario, la matriz elegíaca se impone y el ego enunciador exiliado, anteriormente caracterizado por el tópico del exclusus amator (Miller 2004, 212), se expresa ahora en sintonía con el motivo elegíaco del pauper amator ${ }^{48}$, según el cual los versos del enamorado deben competir con los regalos opulentos que ofrecen sus rivales. Así como el amator no tiene más remedio que contrarrestar su pobreza con poemas que auguran la inmortalización de su amada, el ego de Pont.4.8 le ofrece a Germánico sus carmina que, aunque en apariencia no sean tan valiosos como los templos de mármol, mantendrán vigente su gloria ${ }^{49}$ al sobrevivir al paso del tiempo, al metal y a la piedra (Tabida consumit ferrum lapidemque uetustas / nullaque res maius tempore robur habet, 49-50) ${ }^{50}$. Esto será un beneficio para el protagonista del carmen y para el poeta, con lo cual la inclusión de Germánico como numen ${ }^{51}$ y como personaje literario tendrá amplias repercusiones pues a partir de sus plurivalencias, posibilitará y legitimará la obra de nuestro uates.

Al desempeño de Germánico como soldado y numen se suma su participación como poeta: Non potes officium uatis contemnere uates: / iudicio pretium res habet ista tuo, 67-68. El ego recrea así una instancia de «complicidad profesional» (Rosati 2012, 304) que, una vez más, compromete a Germánico con la literatura ovidiana y lo hace partícipe de ella. Tras mencionar que sus ocupaciones militares alejan a Germánico del ámbito poético (69-70), el ego remarca que, al proporcionar asuntos para la poesía, este princeps sigue vinculado a la actividad literaria (sed dare materiam nobis quam carmina maius, nec tamen ex toto deserere illa potes, 71-72). Tal afirmación deja al descubierto la prevalencia de la literatura a pesar de las circunstancias

\footnotetext{
48 Para este tópico, $c f$. Schniebs y Daujotas (2009, LII-LIII) y López Grégoris (2011), s.u. «Rival».

49 Cf. Pont.4.8.45-48: carmina uestrarum ... praeconia laudum, 45; neue sit actorum fama caduca cauent, 46; carmine fit uiuax uirtus expersque sepulchri, 47; notitiam serae posteritatis habet, 48.

50 Clara es la alusión a Hor.Carm.3.30, ya señalada por Galasso (2008, 4), y Myers $(2014,733)$.

51 Myers (2014, 730-731), indica que con las referencias a personajes del ciclo tebano (Pont.4.8.51-54), la Gigantomaquia (8.57-60) y las apoteosis de Líber, Hércules y Augusto (8.61-64) y sus correspondientes ecos en Metamorphoses, Ovidio justifica los alcances de su poesía y muestra que ya ha creado dioses, con lo cual valida la inmortalidad que proporciona su obra. Rosati (2012) repasa la Gigantomaquia en relación con la literatura encomiástica.
} 
propias de la milicia e instala también al personaje político como numen, miles y uates emblema de asuntos solemnes para ser cantados en un marco elegíaco. La comparación subsiguiente con Apolo sintetiza la misma idea a partir de la perfecta correlación entre estos elementos:

Vtque nec ad citharam nec ad arcum segnis Apollo est, sed uenit ad sacras neruus uterque manus,

sic tibi nec docti desunt nec principis artes, mixta sed est animo cum Ioue Musa tuo. (Pont.4.8.75-78)

Por un lado, la equivalencia entre las múltiples destrezas de Germánico y las de Apolo, dios asociado con la poesía pero también con el arco y la flecha, se destaca textualmente a partir de la simetría verbal que establecen los coordinantes copulativos (nec ad citharam nec ad arcum; neruus uterque; nec docti ... nec principis) a los efectos de recalcar ante el lector el rango «mixto» de Germánico. Por otro lado, la callida iunctura que cierra el verso elegíaco (Ione Musa) pone de manifiesto el carácter ambiguo del personaje y resalta los presupuestos literarios de la producción ovidiana del exilio que, como veremos, también se manifiestan en Fasti.

\section{Germánico en Fasti}

La caracterización de Germánico como hombre de letras, de armas y de poder vuelve a plasmarse en Fasti, donde el personaje es invocado nuevamente como divinidad o agente encargado de avalar la obra y como dedicatario de un texto no ya futuro sino concreto. A la luz de lo constatado en Pont.2.1 y 4.8, no parece casual que los roles de dedicatario y de agente patrocinador recaigan sobre este personaje que, presentado como hombre de armas y de letras, reúne dos cualidades que coexisten también en el poema sobre el tiempo romano:

excipe pacato, Caesar Germanice, uoltu hoc opus et timidae derige nauis iter,

officioque, leuem non auersatus honorem, en tibi deuoto numine dexter ades.

sacra recognosces annalibus eruta priscis et quo sit merito quaeque notata dies.

inuenies illic et festa domestica uobis; saepe tibi pater est, saepe legendus auus,

quaeque ferunt illi, pictos signantia fastos, tu quoque cum Druso praemia fratre feres.

Caesaris arma canant ${ }^{\mathrm{P}}$ alii: ${ }^{\mathrm{H}}$ nos Caesaris aras et quoscumque sacris addidit ille dies.

adnue conanti per laudes ire tuorum deque meo pauidos excute corde metus.

$d a$ mihi te placidum, dederis in carmina uires: ingenium uoltu statque caditque tuo.

pagina iudicium docti subitura mouetur 
principis, ut Clario missa legenda deo.

quae sit enim culti facundia sensimus oris, ciuica pro trepidis cum tulit arma reis.

scimus et, ad nostras cum se tulit impetus artes, ingenii currant flumina quanta tui.

si licet et fas est, uates rege uatis habenas, auspice te felix totus ut annus eat. (Fast.1.3-26)

Nota Fantham $(1985,245)$ que el pasaje se divide en dos unidades de doce versos (3-14; 15-26), marcadas por dos verbos en modo imperativo (excipe, 3; adnue, 15) que apelan a Germánico, primero, como miembro de la gens gobernante y, luego, como hombre de letras. A nuestro modo de ver, la faceta literaria se impone a lo largo de la caracterización del princeps y se encarga de construir poéticamente a este personaje en el que reposan y se tornan explícitas distintas ambigüedades propias del texto. Tanto la literatura como el poder político aparecen en el primer dístico citado, donde el hexámetro apela a Germánico como Caesar, es decir, en relación con la esfera del poder. Se le pide que reciba de buena gana (excipe pacato ${ }^{52}$... uoltu, 3; non auersatus, 5) la obra del poeta (opus, 4) que, no casualmente situada en el pentámetro, se designa mediante la habitual metáfora de la navegación en el marco de una producción de menor envergadura (timidae ... nauis $\left.{ }^{53}, 4\right)$. Esto mismo destaca el verso siguiente que, al definir la obra como leuem ... honorem (5), remite reflexivamente a la ambigüedad del poema mediante la alusión a un asunto solemne (honos) en términos elegíacos (leuis $)^{54}$. La petición de aprobación por parte del poeta en el comienzo de sus Fasti propone a Germánico como dedicatario del texto, según subraya el segundo dístico del pasaje (officio ... tibi deuoto, 5-6), a quien le pide que guíe la senda por la que transitará esta «nave» (derige ... nauis iter, 4$)^{55}$ y le adjudica la inspiración poética (dexter ades, 6) ${ }^{56}$. Esto le otorga a Germánico un carácter divino ya esbozado en Pont.4.8, reforzado aquí por la designación de su poder (numine, 6; adnue, 15) y por la de su homenaje (deuoto, 6). Dado que dicha epístola pone de manifiesto el deseo del uates de continuar con su escritura, la presente caracterización de Germánico y la misma escritura de Fasti permiten pensar que aquel ha actuado, efectivamente, como un dios, al darle al enunciador la posibilidad de continuar con su práctica literaria.

El dístico 13-14 muestra que este homenaje a Germánico (nos, 13) no tendrá como objeto los Caesaris arma (13), entendidos como asunto que atañe a otros (alii, 13), sino que tratará las Caesaris aras (13) y las modificaciones que este ha hecho en el calendario (14). El hexámetro $13^{57}$ destaca esta separación al distribuir los arma y las arae a ambos lados de la cesura $\mathrm{P}$, del mismo modo que la oposición alii ${ }^{\mathrm{H}}$ nos, focalizada por la cesura $\mathrm{H}$ del verso, hace hincapié en la distinción entre otros poemas y Fasti. Si bien esta recusatio inicial rechaza la escritura relacionada con los arma (y, por extensión, con el ámbito genérico de la épica), no excluye del todo los asuntos elevados (sacra, 7; quo ... merito ... notata dies, 8; festa domestica uobis, 9; praemia, 12 ) cuya solemnidad es resaltada por la mención de conmemoraciones antiguas

\footnotetext{
Subias-Konofal $(2003,112-114)$ revisa las implicancias de pacatus en Fasti como término poético.

Cf. Myers (2014, 726-727) se refiere a los alcances metapoéticos del motivo de la nave.

Green $(2004,34)$ vincula este sintagma con Pont.4.8.29-36 y ve aquí una recusatio respecto de la épica.

Cf. Green (2004, 32-33) sugiere la imagen de una obra en proceso.

Para el uso de ades en Fasti, cf. Subias-Konofal (2003, 118-120).

Subias-Konofal $(2003,121)$ destaca las implicancias de este verso.
} 
(annalibus ... priscis, 7 ; pictos ... fastos, 11) que implican la directa exaltación de la domus Augusta. Los versos 9-12 insisten en esto pues aluden a Germánico (uobis, 9) como último eslabón de su cadena genealógica (pater, 10; auus, 10; Druso ... frater, 12), cosa que parece actualizarla y proponer nuevos lineamientos en la construcción del abolengo imperial (tu quoque ... feres, 12). Esto último también se traslada al calendario ovidiano a partir de la ampliación de los alcances poéticos del ego. De hecho, la descripción de estos vínculos familiares se presenta en términos literarios cuando el ego señala que Germánico los hallará mediante la lectura (tibi ... legendus, 10). La posibilidad de que Germánico «lea» los Fasti ovidianos es significativa pues le otorga a la obra una valoración cualitativa y parece sugerir que este princeps, de algún modo, obtendrá algún provecho de esta lectura. No obstante, resulta extraño que Germánico deba encontrar (inuenies, 9) y reconocer (recognosces, 8) cuestiones que remiten a la construcción del poder de su propia familia, así como los temas relativos al calendario tampoco deberían resultarle ajenos al traductor de los Phaenomena de Arato. Al respecto, Green $(2004,34-35)$ indica que el prefijo re- del verbo recognoscere da la pauta de que Germánico ya estaba adecuadamente formado en estos menesteres, con lo cual podemos inferir que su lectura de Fasti es guiada por el ego enunciador y parece apuntar, más que a Germánico, al lector extradiegético ${ }^{58}$ que, a través de aquel, podrá ir encontrando y reconociendo o, mejor dicho, redescubriendo los múltiples alcances del poema sobre el calendario.

El vínculo entre la literatura y el poder político se explicita nuevamente a través de la designación misma del texto (carmina, 17) que celebrará los triunfos (laudes ${ }^{59}$, 15) de la gens Augusta. Al hacer hincapié, una vez más, en el estatuto divino de Germánico (adnue, 15; da, 17), el pasaje remite, como señala Fantham $(1985,248)$ a Verg.Georg.1.40, donde Octavio es invocado con los mismos fines y por medio de un léxico similar ${ }^{60}$. La construcción elegíaca del poder que plantea el pasaje de Fasti retoma y resemantiza la invocación virgiliana, de modo que la conjunción de la elegía y la épica en un texto con ciertos rasgos didácticos vuelve a apelar a la mixtura genérica de la obra ${ }^{61}$. Los versos siguientes confirman esta ambigüedad programática: el pentámetro 18 exhibe la dependencia de Germánico por parte del poeta a través de la similitud fónica y de la correlación sintáctica entre los posibles destinos de su poesía (sTATque cAdiTque), mostrando que el ingenium de nuestro uates está supeditado al uoltus de Germánico mencionado en 1.3, al igual que en Pont.4.8 lo estaba su partida de Tomi. El dístico 19-20 insiste en la configuración literaria de estos vínculos de poder, no solo porque, a medida que se desarrolla esta presentación, la obra es designada mediante una trama léxica propia del quehacer literario y de su recepción (pagina, 19; legenda, 20), sino porque se someterá al juicio de un doctus princeps al igual que en Pont.4.8.7762. Al trasladar a Fasti el motivo que dicha elegía

\footnotetext{
58 A propósito de Hor.Ep.2.1, Barchiesi (1993, 152) observa que la mención del destinatario en un texto didáctico apela al público lector, que en su lectura aprenderá las bases de una nueva literatura.

59 Fantham $(1985,253)$ ve en las laudes la oportunidad de conmemorar la uirtus, elemento relevante al configurar la personalidad del Germánico lector.

60 Da facilem cursum atque audacibus adnue coeptis (VERG.Georg.1.40)

${ }_{61}$ Para Fantham $(1985,248-249)$ el poema ovidiano propone una alternativa de solemnidad patriótica ante los asuntos bélicos de la epopeya a partir de la celebración del héroe nacional como líder religioso y civil que ha traído paz con su victoria.

${ }^{62} C f$. Newlands $(1995,54)$; Myers $(2014,729)$. Green $(2004,40-41)$ propone distintas acepciones e implicancias para pagina.
} 
del exilio incluye en la comparación entre Germánico y Apolo (Clario ... deo, 20), el poema sobre el calendario reactiva la dualidad que ambos comparten en Pont.4.8.75 (citharam; arcum). El dístico 21-22 vuelve a poner de manifiesto tal ambigüedad al resaltar la elocuencia ${ }^{63}$ del dedicatario (culti facundia ... oris, 21 ) y sus actitudes (ciuica $^{64}$... tulit arma, 22), lo cual permite explicitar nuevamente, por medio del personaje de Germánico, el tipo de práctica poética en Fasti.

La idoneidad de Germánico para la literatura queda clara a partir de la relación de su impetus con las artes (23), que adquiere, a su vez, la forma de la metáfora de la escritura como ríos que fluyen (ingenii currant flumina, 24) ${ }^{65}$ mediante elementos léxicos llamativos. En efecto, la imagen del movimiento fluido y permanente que se desprende del verbo currere queda enmarcada en el verso por los términos ingenium y flumina, estructura que destaca la naturalidad con la que Germánico, doctus y semejante a Apolo, despliega su talento literario. Por último, el poeta cierra su proemio con una doble mención de Germánico como poeta y como divinidad. En el primer caso, tal como indica el poliptoton uates - uatis (25), apunta nuevamente a establecer, en términos de Rosati $(2012,304)$, cierta «complicidad profesional», no solo para obtener la aceptación de Germánico sino, también, para identificarlo consigo mismo y recalcar así que tanto el nuevo princeps como el ego pueden conducir una empresa literaria (rege ... habenas, 25): uno como personaje de dicha obra (con todo lo que ello implica) y el otro como poeta. En el segundo, el carácter divino de Germánico (auspice, 26) lo hace partícipe de otro movimiento (eat, 26) que remite al poema mismo a partir de la designación de su asunto (annus, 26) y a su condición $(f e l i x, 26)$ a partir de la intervención del dedicatario. El pedido de aprobación queda, así, justificado desde el mismo quehacer literario al involucrar a este personaje en su rango de poeta, en cuya figura confluyen diversas características, disímiles en apariencia pero constitutivas de un texto que se define a partir de esta singularidad.

La ambigüedad que representa Germánico vuelve a plasmarse en Fasti en otras dos oportunidades. La primera remite a la participación de $\mathrm{Jano}^{66}$ (1.63-288), primera divinidad presente en el texto y entendida como una figura bifocal, vinculada tanto con la paz como con la guerra y cuya aparición da cuenta programáticamente del tipo de literatura que se expone en el calendario ovidiano ${ }^{67}$. La intervención de Jano en el poema está enmarcada por dos invocaciones a Germánico (1.63-64 y 1.285-286) que, en una suerte de composición en anillo, abren y cierran la mención del dios, mostrando así el encuadre de una divinidad ambivalente a partir de un personaje de idénticas características. La segunda discordancia remite al libro 4, que invoca a Germánico durante el mes de Venus, diosa mentora de la poesía elegíaca y vinculada genealógicamente ${ }^{68}$ con la gens Iulia. El proemio del cuarto libro (4.118) retoma algunos elementos de $1.1-26^{69}$ al reiterarle al lector, como en 1.1, que los componentes de su obra (tempora cum causis, 4.11) serán extraídos de antiguos

63 No en vano Ovidio dedica Pont.2.5 a Salano, maestro de retórica de Germánico.

${ }^{64}$ Green (2004, 41-42) advierte el uso del adjetivo ciuicus como «legal aid» que «makes arma generically compatible to elegy by only evoking 'arms' taken up for peaceful purposes».

65 Para los ríos como metáfora del talento literario, $c f$. Green (2004, p.42); Subias-Konofal (2003, 117; 128).

${ }_{66}$ Herbert-Brown (1994, 185-196) revisa la relación entre Germánico y Jano.

67 Para la figura de Jano y sus implicancias en Fasti, cf. Hardie (1991).

68 Pasco-Pranger (2006) desarrolla la cuestión genealógica en Fasti.

69 Fantham $(1985,256-258)$ detecta esas coincidencias y aborda el vínculo entre ambos proemios a la luz de otros pasajes de Fasti. 
anales (annalibus eruta priscis, 4.11). El opus mencionado en 1.4 se encuentra aquí en desarrollo y Venus ordena terminarlo ('coeptum perfice' dixit 'opus', 4.15), para lo cual el ego recibe los materiales necesarios (causae y dierum, 4.17) y finalmente, en 4.18 reaparece la metáfora de la literatura como navegación (nauis eat). A nuestro juicio, resulta significativo que los favores anteriormente solicitados a Germánico se trasladen ahora a Venus, cuya presencia parece vincularse con el marco genérico del poema. Germánico es invocado durante el mes venusino, tras la descripción de la genealogía de Roma (4.19-60) y en medio de la explicación del nombre de la diosa, donde el ego explicita:

\author{
huius erat Solimus Phrygia comes unus ab Ida, \\ a quo Sulmonis moenia nomen habent, \\ Sulmonis gelidi, ${ }^{\mathrm{P}}$ patriae, ${ }^{\mathrm{H}}$ Germanice, nostrae. \\ me miserum, Scythico quam procul illa solo est! (Fast.4.79-82)
}

Tras la mención del presunto origen griego del nombre de Venus - Afrodita (4.6164), el ego enunciador brinda un listado de personajes vinculados con el exilio y el motivo fundacional, que comienza con Evandro y termina con Eneas (4.65-78). Entre los compañeros de este se incluye a un tal Sólimo, probablemente una invención del mismo Ovidio ${ }^{70}$ para justificar el surgimiento de su patria Sulmona, según subraya el entrelazamiento fónico entre ambos nombres (SoLi $\underline{i} \underline{u} S$, 79; SuL LMoni $\underline{\text { S }}$, $80 ; 81)$. El hexámetro 81 ubica la ciudad del poeta en el primer hemistiquio y, en el segundo, enmarca la figura de Germánico con los términos que definen el valor de ese espacio (patriae ... nostrae). Tal disposición destaca el sustantivo patria entre las cesuras $\mathrm{P}$ y H y yuxtapone la mención a Germánico con las alusiones que refieren al poeta (Sulmonis ... Germanice). Si se tiene en cuenta que estos elementos se incluyen en el verso propio de la épica, el texto parecería establecer una simetría entre las alabanzas que merecería la patria del ego y aquellas de las que es digno el mismo Germánico. Más aún, al comenzar con una exclamación elegíaca convencional (me miserum, 82) para aludir a la dolorosa distancia entre su patria y la tierra escita, el enunciador vuelve a presentarse como exclusus (cf. supra). Este gesto reflexivo subyace también en el lamento referido a la patria del poeta, dado que lo asocia con la faceta fundacional de los mencionados héroes exiliados: así como Evandro y Eneas fundarán nuevas ciudades, el enunciador de Fasti se configura como fundador de un proyecto poético. Esto se justifica con la relación etimológica del nombre de Venus - Afrodita con el verbo aperire en 4.85-90 pues permite pensar que el personaje de Germánico (hombre de armas y de letras; dedicatario, divinidad protectora y posible lector del poema elegíaco del calendario; asociado genealógicamente con Augusto, Tiberio y Venus y no casualmente ubicado en un pasaje que remite al exilio del poeta) se convierte en uno de los principales recursos textuales del ego para exponer o «abrir» ante la mirada de sus receptores el proceso mismo de su quehacer literario ${ }^{71}$.

\footnotetext{
Cf. Bomer (1958, 213).

71 Pasco-Pranger $(2006,129)$ compara la Venus ovidiana con la de LuCR.DRN1.1-49 y sostiene que «the Fasti's Venus is both a poetic construct, a representative of the form of elegy and a patroness of poetry, and a didactic one, the propositum of Book 4».
} 


\section{Conclusiones}

La revisión de los principales lineamientos de la construcción de Germánico como personaje en Fasti en relación con la multiplicidad de elementos genéricos que confluyen en el poema ovidiano permite postular que la presentación de dicha figura política como dedicatario y como numen protector e inspirador del poema del calendario no constituye un aspecto periférico de la poética ovidiana del tiempo romano, sino, por el contrario, uno de sus rasgos más representativos. Las características que reúne Germánico en tanto dedicatario y numen son polivalentes, dado que lo muestran como un personaje vinculado tanto con las armas y el poder como con la literatura. Tales rasgos, que comienzan a forjarse en Pont.2.1 y 4.8, hacen de Germánico un personaje ambiguo, que opera como punto de intersección entre elementos elegíacos y épicos, al mismo tiempo que participa de una práctica literaria con pretensiones didácticas. En este sentido, el Germánico de Fasti puede ser entendido como un indicio reflexivo de la hibridez genérica del poema, que retoma, desde un nuevo ángulo, la poética ovidiana de Ex Ponto. El calendario de Roma queda, así, legitimado como tal: una obra de asunto solemne expuesta en dísticos elegíacos, plausible de ser llevada a cabo y con el patrocinio y favor de Germánico.

\section{Referencias bibliográficas}

Alton, E.H., Wormell, D.E.W. y Courtney, E. (2005), P. Ovidii Nasonis Fastorum Libri Sex, Leipzig, Teubner.

Baeza Angulo, E. (2008), «La nueva elegía ovidiana: epistvlae ex exilio», Emérita 76, 253273.

Baldwin, B. (1981), «The Authorship of the "Aratus" Ascribed to Germanicus», QUCC 7, 163-172.

Barchiesi, A. (1993), «Insegnare ad Augusto: Orazio, Epistole 2, 1 e Ovidio, Tristia II», $M D$ 31, 149-184.

- (1997), The Poet and the Prince. Ovid and Augustan Discourse, Berkeley, University of California Press.

Bömer, F. (1957-1958), P. Ovidius Naso. Die Fasten, 2 vols., Heidelberg, Carl Winter Universitätsverlag.

Braccesi, L. (1987), «Germanico e l'imitatio Alexandri in Occidente», Bonamente, G. y Segoloni, M. P. (eds.), Germanico. La persona, la personalità, il personaggio, Atti del Convegno (Macerata-Perugia, 9-11 maggio 1986), Roma, Università Macerata, 53-65.

Calderón Dorda, E. (1990), «Traducciones Latinas perdidas de los Fenómenos de Arato», Myrtia 5, 23-45.

Castilla del Pino, C. (1989), «La construcción del self y la sobreconstrucción del personaje», en Castilla del Pino, C. (comp.), Teoría del personaje, Madrid, Alianza Editorial, 21-38.

Claassen, J. M. (2008), Ovid Revisited. The Poet in Exile, Londres, Bloomsbury.

Conte, G. B. (1992), «Empirical and Theoretical Approaches to Literary Genre», en Galinsky, K. (ed.), The Interpretation of Roman Poetry: Empiricism or Hermeneutics?, Frankfurt, Peter Lang, 104-123.

Cresci Marrone, G. (1987), «Germanico e l'imitatio Alexandri in Oriente», Bonamente, G. y Segoloni, M. P. (eds.), Germanico. La persona, la personalità, il personaggio, Atti del Convegno (Macerata-Perugia, 9-11 maggio 1986), Roma, Università Macerata, 67-77. 
Dalzell, A. (1996), The Criticism of Didactic Poetry. Essays on Lucretius, Vergil and Ovid, Toronto, University of Toronto Press.

Edmunds, L. (2001), Intertextuality and the Reading of Roman Poetry, Baltimore-Londres, The Johns Hopkins University Press.

Fantham, E. (1985), «Ovid's Germanicus and the Composition of the Fasti», PLLS 5, 243281.

Gain, D. B. (1976), The Aratus ascribed to Germanicus Caesar, Londres, The Athlone Press.

Galasso, L. (2008), «Pont. 4, 8: il 'proemio al mezzo' dell'ultima opera ovidiana», Dictynna $5,1-10$.

Genette, G. (2001), Umbrales, trad. Lage, S., México, Siglo XXI.

Giancarlo, B. (2010), «Gli “epigrammi” di Germanico», Rivista di cultura classica e medioevale 52, 81-105.

Green, S. J. (2004), Ovid, Fasti 1: a Commentary, Leiden-Boston, Brill.

Hardie, Ph. (1991), «The Janus Episode in Ovid's Fasti», MD 26, 47-64.

Harrison, S. (2002), «Ovid and Genre: Evolutions of an Elegist», en Hardie, Ph. (ed.), Cambridge Companion to Ovid, Cambridge, Cambridge University Press, 79-94.

Herbert-Brown, G. (1994), Ovid and the Fasti: an Historical Study, Oxford, Oxford Clarendon Press.

King, R. (2004), «Male Homosocial Readership and the Dedication of Ovid's Fasti», Arethusa 37, 197-223.

López Grégoris, R. (2011), s.u. «Rival» en Moreno Soldevila, R. (ed.).

Marcos Casquero, M. A. (1984), Publio Ovidio Nasón. Fastos, Madrid, Editora Nacional.

Martós Fernández, J. (2011), s.u. «Espera» en Moreno Soldevila, R. (ed.).

McGowan, M. M. (2009), Ovid in exile: power and poetic redress in the Tristia and Epistulae ex Ponto, Leiden-Boston, Brill.

Miller, P. A. (2004), Subjecting Verses. Latin Love Elegy and the Emergence of the Real, Princeton, Princeton University Press.

Moreno Soldevila, R. (ed.) (2011), Diccionario de motivos amatorios en la literatura latina (siglos III a. C. - II d. C.), Huelva, Universidad de Huelva.

Moya Del Baño, F. M. (1991), «La función de los mitos en el Zodíaco de Germánico», Fortunatae: Revista canaria de filología, cultura y humanidades clásicas 2, 263-276.

Myers, K. S. (2014), «Ovid, Epistulae ex Ponto 4.8, Germanicus, and the Fasti», CQ 64, 725-734.

Nagle, B. R. (1980), The Poetics of exile: Program and Polemic in the "Tristia" and "Epistulae ex Ponto" of Ovide, Bruxelles, Latomus.

Nicás Montoto, J. M. B. (2004), Revisión del texto, léxico, traducción y comentario de "Los fenómenos de Arato" de Germánico, Madrid. URL: <http://eprints.ucm.es/tesis/fll/ ucm-t27665.pdf $>$ [15/08/2017].

Newlands, C. (1995), Playing with time. Ovid and the Fasti, Ithaca, Cornell University.

Pani, M. (1968), «Il circolo di Germanico», AFMB 7, 109-127.

Pasco-Pranger, M. (2006), Founding the year: Ovid's Fasti and the poetics of the Roman calendar, Leiden-Boston, Brill.

Pichon, R. (1991), Index uerborum amatorium, Hildesheim-Zúrich-Nueva York, Georg Olms Verlag.

Pozzi, M. (2001), «Yo sé que tú sabes que yo sé. Esquemas de la autoridad discursiva en Manilio», en Caballero de del Sastre, E. y Schniebs, A. (eds.), La fides en Roma: Aproximaciones, Buenos Aires, Editorial de la Facultad de Filosofía y Letras de la Universidad de Buenos Aires, 125-150. 
-. (2010), «Aproximaciones a la poesía didáctica latina», en Schniebs, A. (coord.), Debates en Lenguas Clásicas, Buenos Aires, Editorial de la Facultad de Filosofía y Letras de la Universidad de Buenos Aires, 105-130.

Rosati, G. (2012) «Il poeta e il principe del futuro. Ovidio e Germanico su poesia e potere», en Citroni, M. (ed.), Letteratura e civitas. Transizioni dalla Repubblica all'Impero. In recordo di Emanuele Narducci. Pisa, Edizioni ETS, 295-311.

Richmond, J. A. (1990), Ovidius Ex Ponto Libri Quattuor, Leipzig, Teubner.

Salvo, D. (2010), "Germanico e la rivolta delle legioni del Reno», "O $\rho \mu \varsigma$. Ricerche di Storia Antica, 138-156.

Schniebs, A. y Daujotas, G. (2009), Ovidio. Arte de amar, Buenos Aires, Colihue.

Subias-Konofal, V. (2003), «Poésie, politique et rhétorique rituelle: 1'Hymne à Germanicus dans les Fastes d'Ovide», Bulletin de l'Association Guillaume Budé 1, 107-129.

Tola, E. (2004), La métamorphose poétique chez Ovide: Tristes et Pontiques. Le poème inépuisable, Paris-Louvain-Dudley, Peeters.

- (2008), «Chronological Segmentation in Ovid's Tristia: the Implicit Narrative of Elegy», en Liveley, G. y Salzman Mitchell, P. (eds.), Latin Elegy and Narratology. Fragments of Story, Columbus, Ohio University Press, 51-67.

Traver Vera, A.J. (2011), s.u. «Ronda de amor» en Moreno Soldevila, R. (ed.).

Volk, K. (2002), The Poetics of Latin Didactic. Lucretius, Vergil, Ovid, Manilius, Oxford, Oxford University Press. 